\title{
Susceptibility genes for schizophrenia affect normal individuals Nick Stefanis
}

\author{
Address: 1st Department of Psychiatry, Aeginition Hospital, University of Athens, Greece \\ from International Society on Brain and Behaviour: 3rd International Congress on Brain and Behaviour \\ Thessaloniki, Greece. 28 November - 2 December 2007 \\ Published: 17 April 2008 \\ Annals of General Psychiatry 2008, 7(Suppl I):S89 doi:10.1 I86/1744-859X-7-SI-S89
}

This abstract is available from: http://www.annals-general-psychiatry.com/content/7/SI/S89

(C) 2008 Stefanis; licensee BioMed Central Ltd.

In the largest study of its kind to date, we sought to examine the impact of several genes that have been previously associated with schizophrenia susceptibility, such as Catechol-O-methyltransferase (COMT), Neuregulin1 (NRG1), Dysbindin (DTNBP1), D-amino-acid oxidase activator (DAOA), D-amino-acid oxidase (DAAO) and the regulator of G-protein signaling 4 (RGS4), on a healthy population. We recruited more than 2000 young men and measured dimensions of their cognitive abilities and schizotypal personality traits. Healthy individuals who possessed the risk variants within the DNTBP1, NRG1, COMT, DAAO and RGS4 genes exhibited selective and small reductions in their cognitive performance and in general had higher schizotypy scores. Even at the general population level, the genetic liability to psychosis may be expressed as minute and 'undetected to the naked eye' alterations in brain information processing capacity and behavior.

\section{References}

I. Stefanis N.C., et al:: Impact of Schizophrenia Candidate Genes on Schizotypy and Cognitive Endophenotypes at the Population Level. Biological Psychiatry 2007, 62(7):784-792. October 